\title{
ROBOT-BRAND FIT THE INFLUENCE OF BRAND PERSONALITY ON CONSUMER REACTIONS TO SERVICE ROBOT ADOPTION
}

\author{
Sungwoo Choi $^{1} \cdot$ Stella X Liu $^{1} \cdot$ Choongbeom Choi $^{2}$
}

Accepted: 4 January 2022 / Published online: 22 January 2022

(c) The Author(s), under exclusive licence to Springer Science+Business Media, LLC, part of Springer Nature 2022, corrected publication 2022

\begin{abstract}
Can every brand benefit from adopting service robots? To tackle this important question, we examined the interactive effects of brand personality (sincere vs. exciting) and service robot type (high-contact vs. low-contact) on customer reactions to service robot implementation. Results from three experimental studies indicate that customers tend to react negatively to high-contact robots when the brand had a sincere (vs. exciting) personality. This tendency is driven by the poor perceived fit between the sincere brand personality and the implementation of high-contact robots. However, such brand personality effects are mitigated in the adoption of lowcontact robots. For a sincere brand adopting high-contact robots, we suggest that signaling warmth can enhance the perceived brand-robot fit and thereby reduce negative customer reactions.
\end{abstract}

Keywords Service robot $\cdot$ Service technology $\cdot$ Technology adoption $\cdot$ Brand personality $\cdot$ Perceived fit

\section{INTRODUCTION}

Despite the rapid development and considerable potential of service robots, managers may wonder if their deployment of service robots in service processes will be successful with the following critical questions. Will implementing service robots really help us? How will target customers react to our use of service robots? Will they accept the change and use the new services? Managers need to know the answers to these questions because customer acceptance of service

Choongbeom Choi

cbchoi@sejong.ac.kr

1 School of Hotel and Tourism Management, The Chinese University of Hong Kong, Shatin, Hong Kong

2 Department of Hospitality and Tourism Management, Sejong University, Seoul, South Korea 
robots may be critical not only to service productivity (Biehl et al. 2004) but also to brand management (Wünderlich et al. 2013).

Previous research on service robots has focused on how features of service robots and consumer characteristics influence intention to adopt as well as service quality evaluation (e.g., Hermann, 2021). Only a few have examined how firm-level factors influence robot application in the service industry. Although the literature has suggested that the nature of the firm (business-to-consumer vs. business-to-business) and brand positioning (high vs. low equity) might moderate the relationship between the degree of robotics adoption and service quality (Xiao and Kumar, 2021), we still lack understanding of how brand personality, one of the important firm-level factors, can affect customer reactions to service robot implementation.

To address the research gap, we examine the role of brand personality in customer reactions to the implementation of service robots. We focus on the impact of brand given the significance of interrelationships between brand and innovation (Brexendorf et al. 2015). Building on the brand personality literature (Aaker, 1997), we argue that customers hold different expectations of sincere vs. exciting brands in terms of the level of touch (the extent to which customers directly interact with frontline employees), which in turn influence their reactions to high-/ low-contact robot adoption. Our findings make a substantive contribution to the literature by broadening the understanding of service robot implementation via the theoretical lens of brand personality (Aaker, 1997). We also provide meaningful insights into how companies can enhance customer reactions to their adoption of high-contact service robots.

\section{THEORETICAL BACKGROUND}

\subsection{Service Robot Adoption in Service Industry}

The service industry has adopted various types of service robots. Some of the robots have direct interactions with customers. For example, room service robots (e.g., YO2D2 at Yotel Boston) and robot servers (e.g., Penny by Bear Robotics) deliver services to guests face-to-face, and even sometimes engage in communication with them. While others perform repetitive tasks without interacting directly with customers. For instance, robots prepare meals in the kitchen (e.g., Spyce) and vacuum cleaning and disinfection robots (e.g., Whiz by SoftBank Robotics) have been widely deployed during COVID-19. Given the different levels of direct interactivity with customers, we adopt Mersha's (1990) Customer Contact Model and categorize service robots into high-contact and low-contact robots. According to Mersha's (1990) framework, high (vs. low) contact service involves more (vs. less) direct contacts and interactions between the customer and the service provider. Although both types of robots have been increasingly used by service companies, high-contact robots have received relatively more attention in the past service and 
marketing literature than low-contact robots. Hence, the current research examines customer reactions to both high-contact and low-contact robots to close the theoretical gap. We propose that the differential customer reactions to high-/lowcontact robot implementation may be contingent upon brand personality.

\subsection{Service Robot Adoption by Sincere vs. Exciting Brands}

Brand personality, defined as "a set of human-like characteristics customers attribute to a brand" (Aaker, 1997, p. 347), represents the nature of a brand and what it means to customers (Schmitt, 2012). Previous research suggests that sincerity and excitement are the two most prominent and applicable among the Big Five brand personality dimensions (e.g., Aaker et al. 2004). Following this notion, we focus on sincere and exciting brands and examine how customers react to their implementation of service robots. A sincere brand is warm, family-oriented, friendly, traditional, and nurturing; an exciting brand is unique, cool, youthful, up-to-date, and imaginative (Aaker, 1997). Moreover, customers tend to establish stronger relationships with sincere brands than with exciting brands (Aaker, 1997; Aaker et al. 2004). Conversely, exciting brands benefit from incongruent and asymmetrical brand communications (e.g., logo design; Sundar and Noseworthy, 2016).

Building on this notion, we argue that customers are likely to react negatively to high-contact robot adoption by a sincere (vs. exciting) brand. The introduction of high-contact robots by a company can be viewed as reducing interpersonal interaction with guests. High-contact robots may be readily perceived by customers as replacements for human service providers. This may reduce the high-touch nature of the service encounter and thus elicit negative reactions from customers (Giebelhausen et al. 2014). When customers expect companies to show genuine care and kindness toward them (i.e., a communal relationship), they show greater satisfaction with high-touch than high-tech services (Fan and Mattila, 2021). Therefore, we argue that, as customers expect warm qualities from a sincere brand, the decision to deploy high-contact service robots can disconfirm this expectation, resulting in negative customer reactions. In contrast, as customers expect exciting brands to be innovative and trendy in their service offerings, they indicate similar satisfaction toward high-touch and high-tech services (Fan and Mattila, 2021). Therefore, we posit that the adoption of high-contact robots by an exciting brand results in less negative reactions from customers than a sincere brand.

On the other hand, unlike high-contact robots, low-contact robots do not replace interpersonal interactions between the customer and the service provider. Therefore, brand personality effects can be mitigated in the adoption of low-contact robots.

Furthermore, we propose that perceived brand-robot fit can explain customers' different reactions to high-contact/low-contact robot adoption by sincere and exciting brands. When customers believe that a brand's activities fit well with their perceptions and expectations of the brand, they can more easily process and evaluate these activities (Lee and Labroo, 2004; Sirianni et al. 2013). Following this line of reasoning, we argue that the fit between a sincere brand and its 
adoption of high-contact robots is likely to be perceived as poor because replacing human touch on the front line seems mismatched with the brand's personality, resulting in negative customer reactions. However, this effect is unlikely to arise for low-contact robot adoption. Figure 1 illustrates the conceptual framework.

H1: Customers react negatively to high-contact robots adopted by a sincere (vs. exciting) brand, but not to low-contact robot adoption.

H2: Negative customer reactions to high-contact robot adoption by a sincere (vs. exciting) brand are mediated by a poor perceived fit, but no such effects emerge for low-contact robot adoption.

If a sincere brand seeks to use high-contact robots, what should it do to minimize the anticipated negative reactions of customers? We propose that utilizing warmth cues as a protective strategy could offset the perceived mismatch between a sincere brand personality and high-contact robot adoption. According to cue diagnosticity theory (Feldman and Lynch, 1988), customers tend to focus on cues that are particularly relevant to a given evaluation. Building on this notion, we argue that customer evaluation of a sincere brand's service makes interpersonal relationships more salient (Güntürkün et al. 2020). Warmth cues signal a firm's sensitivity to customer needs and the quality of interpersonal relations between customers and service providers (Berry, 1995). Such cues can help a sincere brand reduce customer concerns regarding the replacement of touch with tech as a result of its adoption of high-contact robots.

H3: The presence of a warmth cue mitigates the negative customer reactions to high-contact robot adoption by a sincere (vs. exciting) brand.

\section{Study 1: Real Brand Context}

\subsection{Method}

The study had a 2 (brand personality: sincere vs. exciting) $\times 2$ (robot type: highcontact vs. low-contact) between-subjects design. Two hundred forty-nine US adult consumers $\left(M_{\mathrm{age}}=35.01,67.1 \%\right.$ male $)$ from the Amazon Mechanical Turk consumer panel (MTurk) were randomly assigned to one of the four conditions.

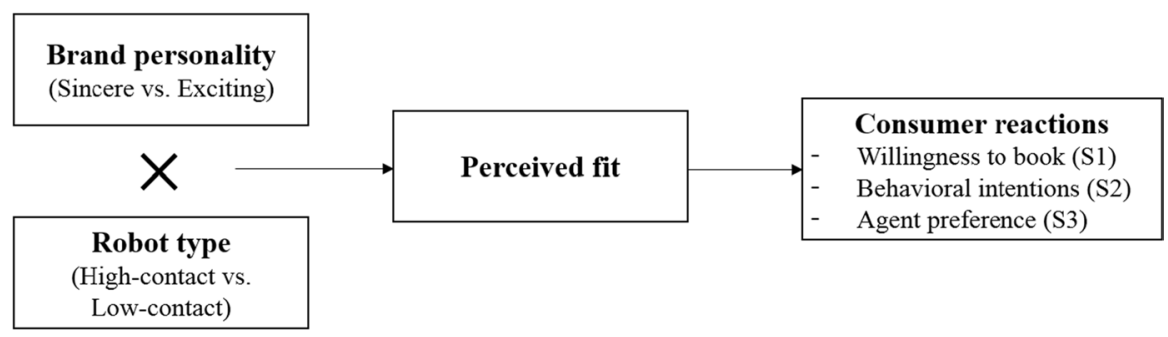

Fig. 1 Conceptual Model of Influence of Brand Personality on Customer Reactions to Service Robot Adoption 

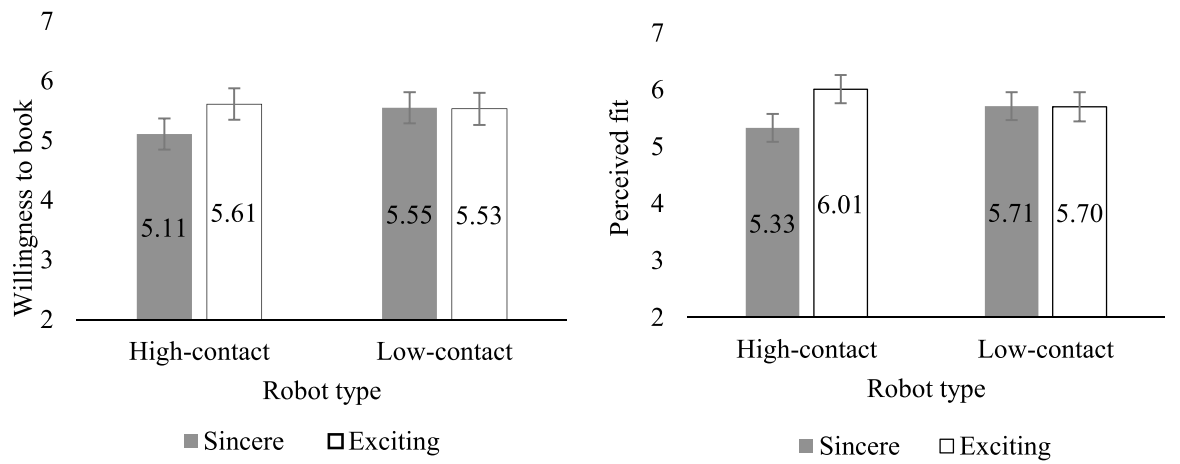

Fig. 2 Interactive Effects of Brand Personality and Robot Type on Willingness to Book and Perceived Robot-Brand Fit

First, we asked the participants to imagine that they had found a deal from Marriott (a sincere brand) or Aloft (an exciting brand) while looking for a hotel staycation package. They were then shown each brand's introductory page, which presented its logo and exterior and interior designs.

We conducted a separate pretest to verify the personalities of the brands. We randomly assigned 71 participants $\left(M_{\text {age }}=38.96,62.0 \%\right.$ male $)$ recruited via Amazon MTurk to one of the two brands. After examining the brand's introduction page, the participants were asked to evaluate the extent to which the brand had sincerity-related on four items (e.g., sincere; $\alpha=0.84$ ) and excitement-related traits on four items (e.g., exciting; $\alpha=0.88)$. The results indicated that Marriott $(M=5.57)$ was perceived as a more sincere brand than Aloft $(M=4.99 ; F(1,69)=4.21, p<0.05)$ and Aloft $(M=6.03)$ as a more exciting brand than Marriott $(M=5.33 ; F(1,69)=7.71, p<0.01)$.

Next, the participants were asked to imagine that the hotel brand had recently introduced service robotic technologies and to read a related announcement. In the high-contact robot condition, the hotel had assigned robots to handle guest interaction tasks, such as check-in and dining service. In the low-contact robot condition, the hotel had assigned robots to handle tasks not involving direct interaction, such as housekeeping and disinfection (see Appendix A). The participants were asked to indicate their willingness to book ( $\alpha=0.82$; adapted from Grewal et al. 1998). They were then asked to rate the robot-brand fit $(r=0.60, p<0.01$; adapted from Cha et al. 2016; see Appendix B). The participants were also asked to indicate familiarity with the hotel brand ( $1=$ not at all familiar, $7=$ very familiar; used as a control variable in subsequent analyses) and provide demographic information.

\subsection{Results}

Willingness to book. A $2 \times 2$ ANCOVA of willingness to book showed a significant brand personality $\times$ robot type interaction $(F(1,244)=3.88, p<0.05$; Fig. 2). The main effects were not significant $(p s>10)$. The participants indicated less willingness to book the sincere brand hotel when it implemented the high-contact 
robots than when the exciting brand did $\left(M_{\text {sincere }}=5.11\right.$ vs. $M_{\text {exciting }}=5.61 ; F(1$, $244)=6.75, p<0.05)$. No such difference emerged for the low-contact robots $\left(M_{\text {sincere }}=5.55\right.$ vs. $\left.M_{\text {exciting }}=5.53 ; F<1\right)$.

[Fig. 2 about here].

Perceived fit. A $2 \times 2$ ANCOVA of perceived fit revealed a significant interaction between brand personality and robot type $(F(1,244)=7.52, p<0.01$; Fig. 2$)$. The main effect of brand personality was significant $(F(1,244)=6.65, p<0.05)$, while the main effect of robot type was not significant $(F<1)$. The participants perceived a poorer fit between the sincere brand and the implementation of highcontact, compared to the exciting brand $\left(M_{\text {sincere }}=5.33\right.$ vs. $M_{\text {exciting }}=6.01 ; F(1$, $244)=14.53, p<0.01)$. No such difference emerged for the low-contact robots $\left(M_{\text {sincere }}=5.71\right.$ vs. $\left.M_{\text {exciting }}=5.70 ; F<1\right)$.

Moderated mediation. We conducted a moderated mediation analysis (Model 8; Hayes, 2017), using the bootstrapping approach (bootstrapping samples $=10,000$ ). The results showed a significant effect of perceived fit on willingness to book $(b=0.68, t=13.00, p<0.01)$, and a significant indirect effect of brand personality via perceived fit on willingness to book for the high-contact robots $(a \times b=-0.46$, $95 \% \mathrm{CI}=-0.74$ to -0.21$)$ but not for the low-contact robots $(a \times b=0.002,95 \%$ $\mathrm{CI}=-0.22$ to 0.22$)$. The index of moderated mediation was significant $(B=-0.47$, $95 \% \mathrm{CI}=-0.80$ to -0.14$)$. These results indicated a moderated mediation effect via perception fit, consistent with $\mathrm{H} 1$ and $\mathrm{H} 2$. Analyses without the control variable had the same pattern of results.

\section{Study 2: Fictitious Brand Context}

\subsection{Method}

The study had a 2 (brand personality: sincere vs. exciting) $\times 2$ (robot type: high-contact vs. low-contact) between-subjects design. Two hundred twenty US adult consumers $\left(M_{\text {age }}=36.59,60.0 \%\right.$ male $)$ from MTurk were randomly assigned to one of the four conditions.

First, the participants were instructed to imagine that they were looking for a resort to visit for their next vacation and found the Instagram page of ACE Resort (a fictitious brand). Following Aaker et al. (2004), sincere vs. exciting brand personality was manipulated through three aspects: (1) brand tagline, (2) content, and (3) color scheme (see Appendix A). After the participants had examined the brand's Instagram page, they were asked to indicate the extent to which the brand showed sincerity-related traits $(\alpha=0.85)$ and excitement-related traits $(\alpha=0.75)$, as a manipulation check. Next, the participants were asked to imagine that the resort brand had recently introduced service robotic technologies and to read the related announcement. We presented the same message as in Study 1, and asked participants to indicate their behavioral intention ( $\alpha=0.92$; Oliver, 1999), followed by the perceived robot-brand fit (as in Study 1; $r=0.77, p<0.01$ ), and demographic details. 


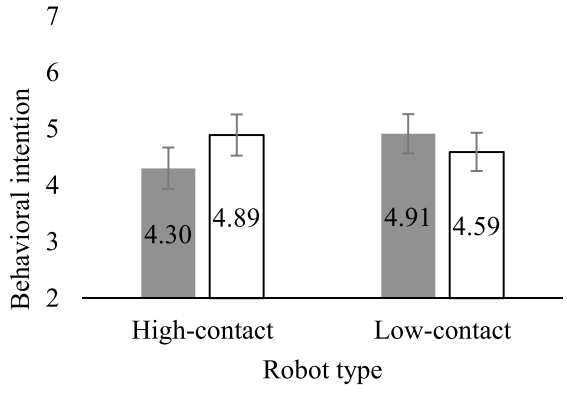

- Sincere $\quad$ Exciting

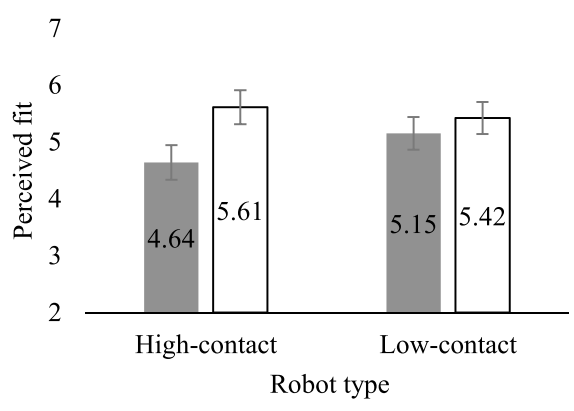

- Sincere $\square$ Exciting

Fig. 3 Interactive Effects of Brand Personality and Robot Type on Behavioral Intention and Perceived Robot-Brand Fit

\subsection{Results}

Manipulation check. One-way ANOVAs of sincerity and excitement perceptions confirmed that the participants evaluated the sincere brand $(M=4.98)$ as more sincere than the exciting brand $(M=4.64 ; F(1,218)=4.11, p<0.05)$ and the exciting brand $(M=5.54)$ as more exciting than the sincere brand $(M=5.22 ; F(1,218)=7.25$, $p<0.01)$. Thus, the manipulation of brand personality was successful.

Behavioral intention. A $2 \times 2$ ANOVA of behavioral intention showed a significant brand personality $\times$ robot type interaction $(F(1,216)=6.27, p<0.05$; Fig. 3$)$. The main effects were not significant $(p s>0.10)$. The participants indicated a weaker behavioral intention when the sincere brand implemented the high-contact robots, compared to when the exciting brand did $\left(M_{\text {sincere }}=4.30\right.$ vs. $M_{\text {exciting }}=4.89$; $F(1,216)=4.99, p<0.05)$. No such difference emerged for the low-contact robot condition $\left(M_{\text {sincere }}=4.91\right.$ vs. $\left.M_{\text {exciting }}=4.59 ; F(1,216)=1.64, p>0.20\right)$.

[Fig. 3 about here].

Perceived fit. A $2 \times 2$ ANOVA of perceived fit revealed a significant brand personality $\times$ robot type interaction $(F(1,216)=5.46, p<0.05$; Fig. 3$)$. The main effect of brand personality was significant $(F(1,216)=16.97, p<0.01)$, while the robot type main effect was not significant $(p>0.10)$. The participants perceived a poorer fit between sincere brand personality and high-contact robots compared with exciting brand personality $\left(M_{\text {sincere }}=4.64\right.$ vs. $\left.M_{\text {exciting }}=5.61 ; F(1,216)=19.59, p<0.01\right)$. No such difference emerged for the low-contact robot condition $\left(M_{\text {sincere }}=5.15 \mathrm{vs}\right.$. $\left.M_{\text {exciting }}=5.42 ; F(1,216)=1.70, p>0.19\right)$.

Moderated mediation. A moderated mediation analysis, as conducted in Study 1 , revealed a significant effect of perceived fit on behavioral intention $(b=0.76$, $t=11.86, p<0.01)$, and a significant indirect effect of brand personality via perceived fit on the behavioral intention for the high-contact robots $(a \times b=0.74,95 \%$ $\mathrm{CI}=0.43$ to 1.06$)$ but not for the low-contact robot $(a \times b=0.20,95 \% \mathrm{CI}=-0.12$ to $0.54)$. The index of moderated mediation was significant $(B=0.53,95 \% \mathrm{CI}=0.09$ to 0.99). These results supported $\mathrm{H} 1$ and $\mathrm{H} 2$. 


\section{Study 3: The Moderating Role of Warmth}

\subsection{Method}

This study had a 2 (brand personality: sincere vs. exciting) $\times 2$ (warmth cue: present vs. control) between-subjects design, holding robot type as high-contact. Two hundred US adult consumers $\left(M_{\text {age }}=38.19,55.5 \%\right.$ male $)$ from MTurk were randomly assigned to one of the four conditions.

First, we manipulated brand personality using the same stimuli as in Study 2. Next, the participants were asked to imagine that they had booked and arrived at the resort. On entering the resort, they had found that the resort had two check-in options: human staff or a concierge robot. We then presented a message from the resort (e.g., "We proudly present our new concierge robots"). In the warmth cue condition, we added the following text at the end of the message: "Concierge robots allow human staff to focus on meeting the more complex needs of our guests and delivering an excellent service" (adapted from Mende et al. 2018). In the control condition, this sentence was not shown. Then, we asked the participants to indicate whether they preferred to be served by human staff or by concierge robots $(1=$ definitely by human staff, $7=$ definitely by concierge robots; Hou et al. 2020). Next, they were asked to rate the robot-brand fit (as in Study $1 ; r=0.84, p<0.01$ ) and provide their demographic details.

\subsection{Results}

Manipulation check. One-way ANOVAs of sincerity and excitement perceptions confirmed that the participants evaluated the sincere brand $(M=5.10)$ as more sincere than the exciting brand $(M=4.57 ; F(1,198)=8.60, p<0.01)$ and the exciting brand $(M=5.69)$ as more exciting than the sincere brand $(M=5.37 ; F(1,198)=5.88$, $p<0.05)$. Thus, the manipulation of brand personality was successful.

Agent preference. A $2 \times 2$ ANOVA of agent preference showed a significant interaction between brand personality and the warmth cue $(F(1,196)=6.17, p<0.05$; Fig. 4). The main effects were not significant ( $p s>0.10)$. In the control condition, the participants indicated a stronger preference to be served by concierge robots when they were implemented by the exciting (vs. sincere) brand $\left(M_{\text {sincere }}=3.76\right.$ vs. $\left.M_{\text {exciting }}=4.52 ; F(1,196)=4.10, p<0.05\right)$. No such difference emerged in the warmth cue present condition $\left(M_{\text {sincere }}=4.73\right.$ vs. $M_{\text {exciting }}=4.16 ; F(1,196)=2.23$, $p>0.13)$.

[Fig. 4 about here].

Perceived fit. A $2 \times 2$ ANOVA of perceived fit revealed a significant brand personality and warmth cue interaction $(F(1,196)=4.55, p<0.05$; Fig. 4$)$. The brand personality $(F(1,196)=11.82, p<0.01)$ and the warmth cue $(F(1,196)=4.80$, $p<0.05)$ main effects were significant. In the control condition, the participants perceived a poorer fit between the sincere brand and its implementation of concierge robots compared to the exciting brand $\left(M_{\text {sincere }}=4.06\right.$ vs. $M_{\text {exciting }}=5.19 ; F(1$, 

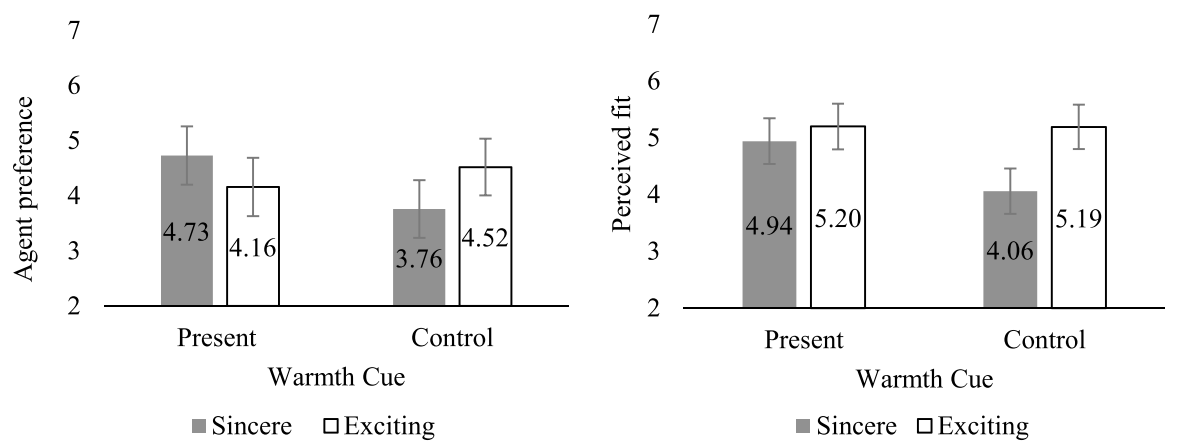

Fig. 4 Interactive Effects of Brand Personality and Warmth Cue on Agent Preference and Perceived Robot-Brand Fit

$196)=15.83, p<0.01)$. No such difference emerged in the warmth cue present condition $\left(M_{\text {sincere }}=4.94\right.$ vs. $\left.M_{\text {exciting }}=5.20 ; F(1,196)<1\right)$.

Moderated mediation. A moderated mediation analysis, as conducted in Study 1, showed a significant effect of perceived fit on agent preference $(b=0.54, t=6.28$, $p<0.01)$, and a significant indirect effect of the brand personality via perceived fit on agent preference in the control condition $(a \times b=-0.61,95 \% \mathrm{CI}=-1.03$ to -0.27$)$ but not in the warmth cue present condition $(a \times b=-0.14,95 \% \mathrm{CI}=-0.45$ to 0.16$)$. The index of moderated mediation was significant $(B=0.47,95 \% \mathrm{CI}=0.04$ to 0.99$)$. Overall, these results supported $\mathrm{H} 3$.

\section{DISCUSSION}

In the wave of service robotics, we still lack an understanding of the role of brand personality in consumer reactions to implementations of service robots. To address this research gap, we investigated customer reactions to the adoption of robots by companies depending on robot type (high-contact vs. low-contact) and brand personality (sincere vs. exciting). The results of our three studies indicate that customers tend to react negatively to the adoption of high-contact robots by a sincere (vs. exciting) brand, which was driven by customer perceptions of the mismatch between the sincere brand personality and the use of robots.

Our research contributes to the literature on brand personality and service technology management. Research has found that strategic implementations such as brand extensions (e.g., Aaker and Keller, 1990) and corporate social responsibility activities (e.g., Cha et al. 2016) should be aligned with a firm's brand personality to enhance customer evaluation. Adding to this stream of research, we found that the implementation of high-contact robots by a sincere (vs. exciting) brand could generate negative customer reactions because it did not fit with the brand personality (i.e., replacing the touch with tech services is not perceived as sincere). This difference in reactions to a sincere versus an exciting brand is less likely to arise for low-contact 
robots. We also extend the previous literature on the important role of warmth in consumer perceptions toward service robots (e.g., Choi et al. 2021; Kim et al. 2019). Study 3 shows that a sincere brand can leverage warmth cues during robot adoption to help justify its use of robots and persuade customers that replacing the touch with tech services is well-matched with its sincere brand personality. The findings provide important insights for firms seeking to enhance customer reactions to their adoption of service robots, especially high-contact robots.

Moreover, our findings suggest that managers should be attentive to brand personality to ensure that customers perceive a fit between the brand personality and robot use. Brand personality is based on customer perceptions, which develop in response to brand features (e.g., logo, packaging) and the types of products and services that brands offer (e.g., Sundar and Noseworthy, 2016). Hence, for established brands, managers should first understand how their target customers view their brand personality. For example, sincere brands need to carefully implement high-contact robots (e.g., concierge robots and robot servers) to minimize negative reactions from their target guests. However, this does not necessarily mean that a sincere brand should not adopt high-contact robots. As demonstrated in Study 3, signaling warmth can alleviate negative reactions to high-contact robot implementation by a sincere brand. A sincere brand that wants to implement high-contact robots should put extra effort into managing the delivery of high-quality services by human employees. Exciting brands, on the other hand, are more flexible in adopting highcontact robots, as their target customers expect them to introduce advanced technologies to convey a youthful and trendy personality.

Furthermore, the findings of Studies 2 and 3 offer managerial insights into brand management for new brands. Following Aaker (1997), the findings suggest that different color schemes and content can be manipulated to lead people to perceive the same brand as either sincere or exciting. Thus, based on their online content, not only well-known brands but also new brands can predict how customers will view their brand personality, and thus how customers will react to their implementation of high-contact/low-contact robots. For new brands focusing on providing warm and high-touch services (i.e., sincere brands), the adoption of high-contact robots should be approached with caution, as the target customers may not regard this as well-matched with the brand personality. However, highlighting the social benefits of robot implementation may to some extent attenuates negative customer reactions. In contrast, new brands seeking to project a youthful, unique, and trendy personality (i.e., exciting brands) may benefit from robot implementation, because the adoption of new technology, whether high-contact or low-contact, aligns well with their brand personality.

We acknowledge several limitations of our research. This research focused solely on the hospitality context where arguably focuses on communal norms that align with the importance of warmth (Mende et al. 2018). It would be worth investigating the effects of brand personality and robot types in other service settings that focus on exchange norms. In a similar vein, it would also be interesting to explore how consumption goals (e.g., a utilitarian business trip vs. a hedonic vacation) influence the interactive effects of brand personality and robot type on customer reactions to robot implementation (e.g., Scarpi, 2021). Moreover, 
individual-level customer variables, such as technology readiness (Parasuraman, 2000), may influence customer reactions to high-contact/low-contact robot implementation. Customers who are more technology ready, e.g., better prepared to embrace and use new technology (Carbonell et al. 2004), may react less negatively to high-contact robot adoption by a sincere brand. Finally, we acknowledge potential empirical issues, such as the position of brand personality manipulation check items and test of alternative explanations. Future research should measure multiple processes to help alleviate such concerns and rule out alternative accounts (e.g., brand authenticity; Sundar and Noseworthy, 2016). In sum, we encourage future researchers to examine additional variables to draw a more complete picture of the effects of companies' brand personalities on robot adoption.

\section{Appendix}

\section{A. Scenarios and stimuli}

\section{Study 1}

While looking for a hotel staycation package, you find a great deal from Marriott [Aloft].
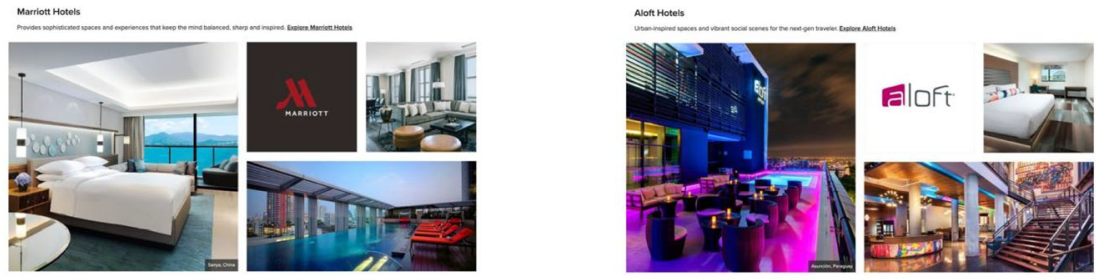

Now, please imagine that Marriott [Aloft] announces new service technology implementations not only to provide comfort for the guest but also to show how serious the brand is taking health and safety. Please see the following message from Marriott [Aloft].

[High-contact robots]

HOW WE ARE MAKING OUR HOTEL SAFE

We are ready to roll out the following features, above and beyond all other government guidance, to ensure you can feel as relaxed as possible while staying with us.

- In addition to current technology, we launch a new mobile application for check-in and keyless entry for your convenience and safety. If you have any questions, our concierge robots will help you solve problems.

- The next time you order room service, our robot butlers are now making contactless deliveries directly to guestrooms.

-At our dining facilities, your table will be served by our robot servers, which will take your order, deliver dishes, and take care of your special requests.

[Low-contact robots]

HOW WE ARE MAKING OUR HOTEL SAFE

We are ready to roll out the following features, above and beyond all other government guidance, to ensure you can feel as relaxed as possible while staying with us.

- We now use vacuum cleaning robots and UV-C robots, designed to sanitize guestrooms as a whole. These robots help kill bacteria and viruses on floors and carpet, through fast coverage of complex and hard-to-reach surfaces.

- Using our new mobile application, guests can reserve housekeeping service and confirm when they leave the room. Once cleaning is complete, the guest will be notified that they can return.

- At our dining facilities, robot chefs are ready to cook your meals. 


\section{Study 2 \& 3}

Imagine that you are looking for a resort to visit during the next holiday. While searching online, you found Instagram page of ACE Resort as shown below.
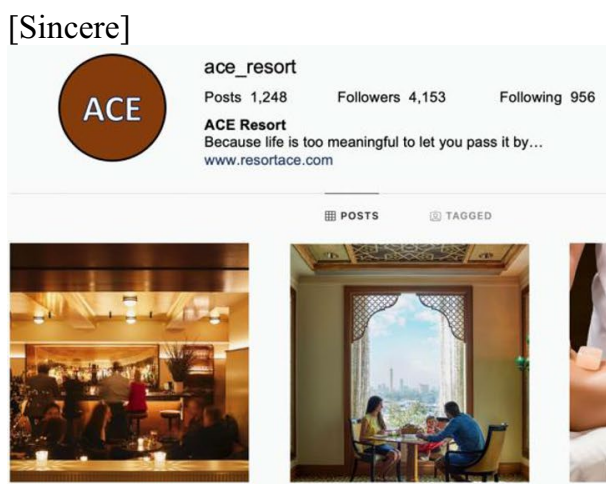

MPOSTS D TAGOED
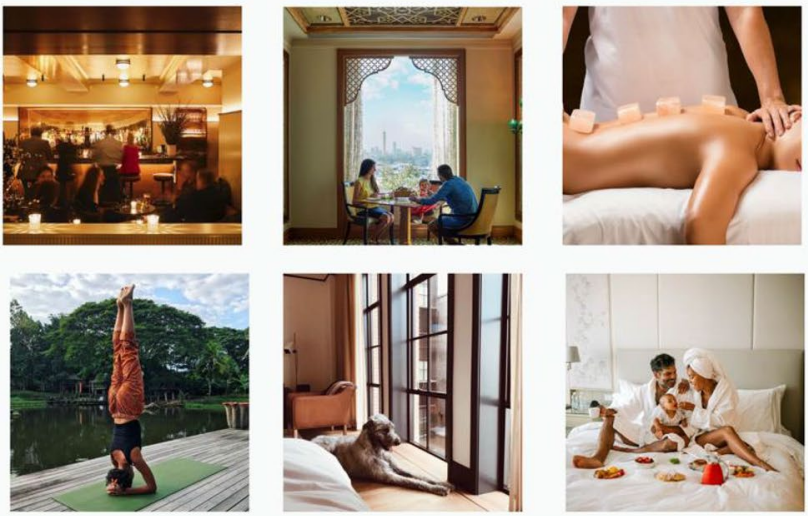

[Exciting]

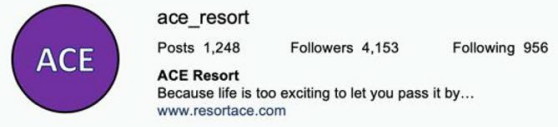

$$
\overline{\text { 田 Posts }}
$$
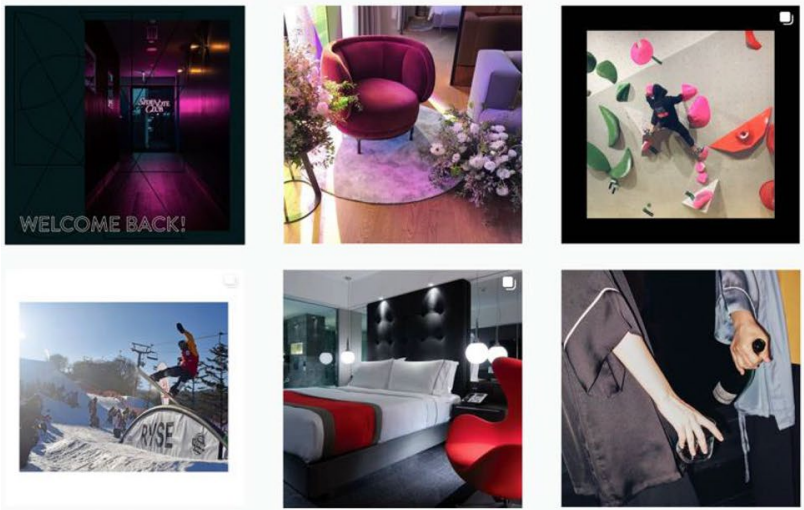


\section{B. Measurement Items}

Study Measures $\quad$ Source

1 Willingness to book ( 1 = very low, 7 = very high $)$

Grewal, Monroe, \& Krishnan (1998)

1. If I were going to reserve a hotel room, the probability of reserving this hotel brand's room is ...

2. The probability that I would consider reserving this hotel brand's room is ...

3. The likelihood that I would reserve this hotel brand's room is ...

Perceived fit ( $1=$ strongly disagree, $7=$ strongly agree $)$

1. This hotel brand's new technology implementations are well matched with its brand image.

2. This hotel brand's new technology implementations are well consistent with its brand image.

2 Behavioral intentions ( 1 = strongly disagree, 7 =

Oliver (1999) strongly agree)

1. I will choose this resort brand in the future.

2. I will prefer to choose this resort brand to other brands.

3. I will recommend this resort brand to someone else.

Perceived fit ( 1 = strongly disagree, 7 = strongly agree)

1. This resort brand's new technology implementations are well matched with its brand image.

2. This resort brand's new technology implementations are well consistent with its brand image.

3 Agent preference ( 1 = definitely by human staff, $7=$ definitely by concierge robots)

When you are checking into this resort, do you prefer to be served by human staff or by concierge robots?

Perceived fit (same as Study 2)

Cha, Yi, \& Bagozzi (2016)

Cha, Yi, \& Bagozzi (2016)

Hou, Zhang, \& Li (2020)

Cha, Yi, \& Bagozzi (2016)

Funding Ministry of Education of the Republic of Korea and the National Research Foundation of Korea,NRF-2020S1A5A8042242,Choongbeom Choi

-All authors equally contributed to the study conception and design. All authors read and approved the final manuscript.

-This work was supported by the Ministry of Education of the Republic of Korea and the National Research Foundation of Korea (NRF-2020S1A5A8042242)

\section{References}

Aaker, J. L. (1997). Dimensions of brand personality. Journal of Marketing Research, 34(3), 347-356. Aaker, D. A., \& Keller, K. L. (1990). Consumer evaluations of brand extensions. Journal of Marketing, 54(1), 27-41.

Aaker, J., Fournier, S., \& Brasel, S. A. (2004). When good brands do bad. Journal of Consumer Research, 31(1), 1-16.

Berry, L. L. (1995). Relationship marketing of services: Growing interest, emerging perspectives. Journal of the Academy of Marketing Science, 23(4), 236-245. 
Biehl, M., Prater, E., \& McIntyre, J. R. (2004). Remote repair, diagnostics, and maintenance. Communications of the ACM, 47(11), 100-106.

Brexendorf, T. O., Bayus, B., \& Keller, K. L. (2015). Understanding the interplay between brand and innovation management: Findings and future research directions. Journal of the Academy of Marketing Science, 43(5), 548-557.

Carbonell, P., Escudero, A. I. R., \& Aleman, J. L. M. (2004). Technology newness and impact of go/ no-go criteria on new product success. Marketing Letters, 15(2), 81-97.

Cha, M. K., Yi, Y., \& Bagozzi, R. P. (2016). Effects of customer participation in corporate social responsibility (CSR) programs on the CSR-brand fit and brand loyalty. Cornell Hospitality Quarterly, 57(3), 235-249.

Choi, S., Mattila, A. S., \& Bolton, L. E. (2021). To Err Is Human(-oid): How Do Consumers React to Robot Service Failure and Recovery? Journal of Service Research, 24(3), 354-371.

Fan, A., \& Mattila, A. S. (2021). Touch versus tech in service encounters. Cornell Hospitality Quarterly, 62(4), 468-481.

Feldman, J. M., \& Lynch, J. G. (1988). Self-generated validity and other effects of measurement on belief, attitude, intention, and behavior. Journal of Applied Psychology, 73(3), 421-435.

Giebelhausen, M., Robinson, S. G., Sirianni, N. J., \& Brady, M. K. (2014). Touch versus tech: When technology functions as a barrier or a benefit to service encounters. Journal of Marketing, 78(4), 113-124.

Grewal, D., Monroe, K. B., \& Krishnan, R. (1998). The effects of price-comparison advertising on buyers' perceptions of acquisition value, transaction value, and behavioral intentions. Journal of Marketing, 62(2), 46-59.

Güntürkün, P., Haumann, T., \& Mikolon, S. (2020). Disentangling the differential roles of warmth and competence judgments in customer-service provider relationships. Journal of Service Research, 23(4), 476-503.

Hayes, A. F. (2017). Introduction to mediation, moderation, and conditional process analysis: A regression-based approach. Guilford Publications.

Hermann, E. (2021). Anthropomorphized artificial intelligence, attachment, and consumer behavior. Marketing Letters, 1-6.

Hou, Y., Zhang, K., \& Li, G. (2020). Service robots or human staff: How social crowding shapes tourist preferences. Tourism Management, 83, 104242.

Kim, S. Y., Schmitt, B. H., \& Thalmann, N. M. (2019). Eliza in the uncanny valley: Anthropomorphizing consumer robots increases their perceived warmth but decreases liking. Marketing Letters, 30(1), 1-12.

Lee, A. Y., \& Labroo, A. A. (2004). The effect of conceptual and perceptual fluency on brand evaluation. Journal of Marketing Research, 41(2), 151-165.

Li, X., Chan, K. W., \& Kim, S. (2019). Service with emoticons: How customers interpret employee use of emoticons in online service encounters. Journal of Consumer Research, 45(5), 973-987.

Mende, M., Scott, M. L., \& Bolton, L. E. (2018). All that glitters is not gold: The penalty effect of conspicuous consumption in services and how it changes with customers and contexts. Journal of Service Research, 21(4), 405-420.

Mersha, T. (1990). Enhancing the customer contact model. Journal of Operations Management, 9(3), 391-405.

Oliver, R. L. (1999). Whence consumer loyalty? Journal of Marketing, 63(4), 33-44.

Parasuraman, A. (2000). Technology Readiness Index (TRI): A multiple-item scale to measure readiness to embrace new technologies. Journal of Service Research, 2(4), 307-320.

Scarpi, D. (2021). A construal-level approach to hedonic and utilitarian shopping orientation. Marketing Letters, 32(2), 261-271.

Schmitt, B. (2012). The consumer psychology of brands. Journal of Consumer Psychology, 22(1), 7-17.

Sirianni, N. J., Bitner, M. J., Brown, S. W., \& Mandel, N. (2013). Branded service encounters: Strategically aligning employee behavior with the brand positioning. Journal of Marketing, 77(6), 108-123.

Sundar, A., \& Noseworthy, T. J. (2016). Too exciting to fail, too sincere to succeed: The effects of brand personality on sensory disconfirmation. Journal of Consumer Research, 43(1), 44-67.

Wünderlich, N. V., Wangenheim, F. V., \& Bitner, M. J. (2013). High tech and high touch: A framework for understanding user attitudes and behaviors related to smart interactive services. Journal of Service Research, 16(1), 3-20.

Xiao, L., \& Kumar, V. (2021). Robotics for customer service: A useful complement or an ultimate substitute? Journal of Service Research, 24(1), 9-29.

Publisher's Note Springer Nature remains neutral with regard to jurisdictional claims in published maps and institutional affiliations. 